\title{
Research status of human resource management in China based on scientific knowledge map
}

\author{
Kun Qian, Yingxue $\mathrm{Li}^{*}$, Yuenan Lv , and Xiaonan Yang \\ School of management, Dalian Polytechnic University, Ganjingzi District, Dalian, Liaoning, China
}

\begin{abstract}
In order to accurately grasp the current research frontier of human resource management, according to certain retrieval conditions, 2724 literatures published from 2011 to 2021 were retrieved from CNKI database as data samples. CiteSpace software was used for visual analysis, $\mathrm{CO}$ citation analysis and cluster analysis were carried out on these literature data, and the corresponding knowledge map was drawn. The objective of this paper is to show the hot topics and cutting-edge trends of human resource management research in China and draw the current situation of human resource management research in China, in order to provide reference for future research.
\end{abstract}

\section{Introduction}

Since the reform and opening up, China has made great achievements. In 1954, Peter Drucker put forward the important concept of "human resource" in his book the practice of management. People gradually realized the importance of human resource to the development of organization. After a series of improvement and development, human resource management now refers to a series of activities under the guidance of economics and humanism, which effectively uses the relevant human resources inside and outside the organization through recruitment, selection, training, compensation and other management forms, meets the needs of the current and future development of the organization, and ensures the realization of organizational goals and the maximization of member development[1-3]. It is the whole process of forecasting the demand of human resource and making the plan of human resource demand, recruiting and selecting personnel and organizing effectively, assessing performance, paying compensation and motivating effectively, and developing effectively according to the needs of organization and individual so as to realize the optimal organizational performance. It is also an important position in the company. Academic circles generally divide human resource management into six modules: 1 . Human resource planning; 2. Recruitment and allocation; 3. Training and development; 4. Performance management; 5. Salary and welfare management; 6. Labor relations management[4].

At present, there are many researches on human resource management in China, but there are few systematic collation and analysis of the current research. Therefore, this paper uses CiteSpace software to comb the domestic literature in the field of human resource

\footnotetext{
* Corresponding author: 2393213813@qq.com
}

management, in order to explore the hot areas of human resource management research, and provide the basis for future research.

\section{Materials and Methods}

\subsection{Data Sources}

This paper analyzes the data from CNKI full-text database, and selects "advanced search" to enter CNKI database. The search condition is "subject" = human resource management, the data source is "Journal", the journal category is "core journal" and "CSSCI", and the publication time is from 2011 to 2021. Other search conditions default, and 3109 initial literatures are obtained. In order to ensure the accuracy of the data, the retrieved literature data were checked one by one, and the duplicate literature and meeting notice were deleted 2724 valid articles were analyzed. (the data retrieval is up to March 17, 2021)

\subsection{Research Method}

In this paper, CiteSpace information visualization software is used to draw knowledge map and analyze data. Professor Chen Chaomei of School of computer and information science of Dreiser University developed CiteSpace information visualization software on the application platform of Java, which is widely used in more than 60 fields such as natural science, engineering and technology science, computer science, etc[5]. In this study, according to the data retrieval results of CNKI, the time span was set as 2011-2021, the time slice was selected as 1 year, the threshold was selected as the top 50, and the citation frequency, $\mathrm{CO}$ citation frequency and co citation system (C, CC and $\mathrm{CCV}$ ) were set as 2, 2 and 20 
respectively.

\section{Results \& Discussion}

\subsection{Bibliometric Analysis}

\subsubsection{Author Distribution}

Through the analysis of the amount of articles published by authors and the map of cooperation network, we can understand the distribution and cooperation of the authors of human resource management research literature. The author collaboration network map of human resource management research literature is shown in Figure 1. The author collaboration map consists of 413 nodes, which indicates that 2724 papers involve 413 signed authors, among which 20 papers are more than 5 , with a total of 199 papers; 11 papers are more than 8 , with a total of 143 papers (see Table 1). These authors can be regarded as the core authors of human resource management research literature. At the same time, the author cooperation map includes 194 links, which shows that the cooperation between authors has reached 194 times. As can be seen from Figure 1, Zhao Shuming published the most relevant literature and cooperated with other authors. However, the network density of the map is only 0.0023 , which indicates that the cooperation strength among the authors of human resource management research literature is low, and there is still a lack of stable cooperation groups.

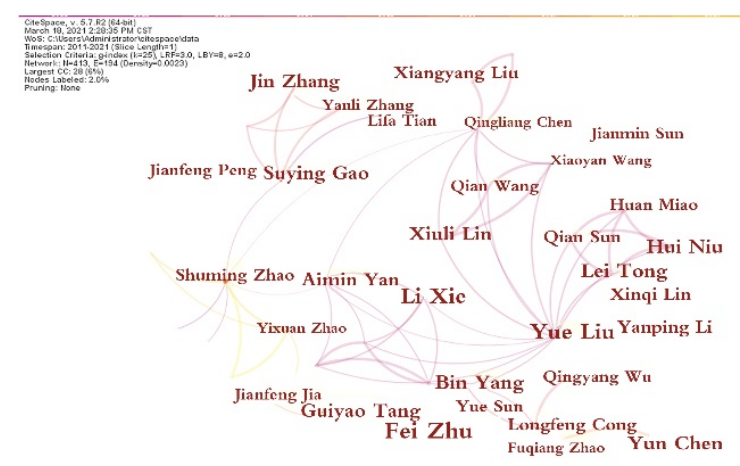

Figure 1 co-occurrence network of human resource management research authors

Table 1 the authors who published more than 8 literatures on human resource management

\begin{tabular}{|c|c|c|}
\hline sort & Number of papers / article & author \\
\hline 1 & 31 & Shuming Zhao \\
\hline 2 & 21 & Shanshi Liu \\
\hline 3 & 16 & Jianfeng Peng \\
\hline 4 & 12 & Guiyao Tang \\
\hline 5 & 11 & Suying Gao \\
\hline 6 & 11 & Hongjun Fang \\
\hline 7 & 9 & Bin Yang \\
\hline 8 & 8 & Yanping Li \\
\hline 9 & 8 & Yue Liu \\
\hline 10 & 8 & Min Zhang \\
\hline 11 & 8 & Longfeng Cong \\
\hline
\end{tabular}

\subsubsection{Organization Distribution}

Through the analysis of the organization cooperation network map of human resource management research literature, we can understand the distribution and mutual cooperation of important organizations.Among the 2724 papers, 408 research institutions were involved, of which 8 published more than 15 papers, with a total of 245 papers. The top three institutions were School of labor and personnel of Renmin University of China (66 papers), School of business of Nanjing University (50 papers) and School of Business Administration of South China University of Technology (44 papers).The map contains 201 links, indicating that cooperation between institutions has reached 201 times. The circle size of each node shows the number of papers published by the organization. The connection between the two nodes represents the cooperative relationship between the two organizations. The more connections between each node and other nodes, the more cooperative relationship between the organization and other organizations. As can be seen from Figure 2, the school of labor and personnel of Renmin University of China publishes the most papers and has more cooperative relations with other institutions. However, the overall network density is only 0.0024 , which indicates that the cooperation intensity between the institutions publishing human resource management research literature is low, and there is still a lack of stable cooperation groups.

Table 2 top 10 organizations publishing research literature on human resource management

\begin{tabular}{|c|c|c|}
\hline sort & $\begin{array}{c}\text { Number of papers / } \\
\text { article }\end{array}$ & mechanism \\
\hline 1 & 66 & $\begin{array}{l}\text { School of labor and } \\
\text { personnel, Renmin } \\
\text { University of China }\end{array}$ \\
\hline 2 & 50 & $\begin{array}{l}\text { Business School of } \\
\text { Nanjing University }\end{array}$ \\
\hline 3 & 44 & $\begin{array}{l}\text { School of business } \\
\text { administration, South } \\
\text { China University of } \\
\text { Technology }\end{array}$ \\
\hline 4 & 20 & $\begin{array}{c}\text { Business School of } \\
\text { Renmin University of } \\
\text { China }\end{array}$ \\
\hline 5 & 18 & $\begin{array}{l}\text { School of management, } \\
\text { Xi'an Jiaotong University }\end{array}$ \\
\hline 6 & 17 & $\begin{array}{l}\text { School of management, } \\
\text { Shandong University }\end{array}$ \\
\hline 7 & 15 & $\begin{array}{l}\text { Business School of } \\
\text { Nankai University }\end{array}$ \\
\hline 8 & 15 & $\begin{array}{l}\text { School of economics and } \\
\text { management, Wuhan } \\
\text { University }\end{array}$ \\
\hline 9 & 13 & $\begin{array}{l}\text { Guanghua School of } \\
\text { management, Peking } \\
\text { University }\end{array}$ \\
\hline 10 & 13 & $\begin{array}{c}\text { School of public } \\
\text { administration, Renmin } \\
\text { University of China }\end{array}$ \\
\hline
\end{tabular}




\subsection{Visual Analysis}

\subsubsection{Keyword Analysis}

Through the co-occurrence analysis of keywords in human resource management research literature, we can see the distribution of high-frequency keywords, which reflects the research hotspots in the field of human resource management[6]. Human resource management research keyword co-occurrence knowledge map is shown in Figure 2.

There are 605 nodes in the knowledge map, which shows that there are 605 keywords in 2724 literatures, of which 10 keywords appear more than 40 times (see Table 3 ). They are human resource management, human resource, strategic human resource management, human resource management practice, enterprise, management, enterprise performance, performance management, small and medium-sized enterprises, enterprise human resource management Key words represent the focus of domestic human resource management research. It can be seen from table 3 that human resource management, human resource management and strategic human resource management have the highest frequency.

\subsubsection{Analysis of research hotspots}

Cluster analysis of keywords can further analyze the subject areas and scope of human resource management research in China. 12 clusters can be obtained, namely, human resource management, management, New Coronavirus pneumonia, human resource management system, competency, compliance review, human resource management system, organization performance, management mode, enterprise management, human resource management theory, and human resource system. It shows the hot areas of human resource management research in China.

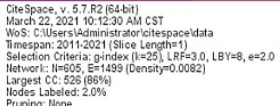

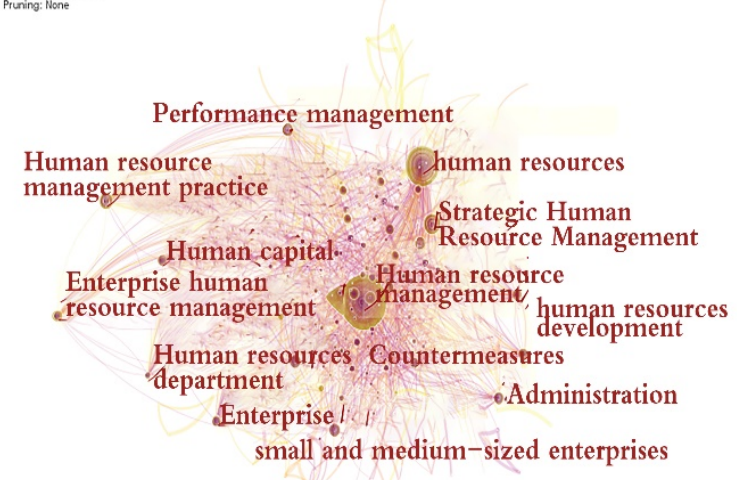

Figure 2 keyword co-occurrence network
Table 3 top ten keywords of human resource management research

\begin{tabular}{|c|c|c|c|}
\hline sort & keyword & $\begin{array}{c}\text { Frequency } \\
\text { of } \\
\text { occurrence }\end{array}$ & $\begin{array}{l}\text { Year of first } \\
\text { appearance }\end{array}$ \\
\hline 1 & $\begin{array}{c}\text { Human } \\
\text { Resource } \\
\text { Management }\end{array}$ & 917 & 2011 \\
\hline 2 & $\begin{array}{l}\text { Human } \\
\text { Resource }\end{array}$ & 410 & 2011 \\
\hline 3 & $\begin{array}{c}\text { Strategic } \\
\text { Human } \\
\text { Resource } \\
\text { Management }\end{array}$ & 83 & 2011 \\
\hline 4 & $\begin{array}{c}\text { Human resource } \\
\text { management } \\
\text { practice }\end{array}$ & 65 & 2011 \\
\hline 5 & enterprise & 58 & 2011 \\
\hline 6 & management & 57 & 2011 \\
\hline 7 & $\begin{array}{c}\text { Enterprise } \\
\text { performance }\end{array}$ & 47 & 2011 \\
\hline 8 & $\begin{array}{l}\text { performance } \\
\text { management }\end{array}$ & 47 & 2011 \\
\hline 9 & $\begin{array}{l}\text { small and } \\
\text { medium-sized } \\
\text { enterprises }\end{array}$ & 46 & 2011 \\
\hline 10 & $\begin{array}{c}\text { Enterprise } \\
\text { human resource } \\
\text { management }\end{array}$ & 41 & 2011 \\
\hline
\end{tabular}

\subsubsection{Evolution of research development trend}

In order to comprehensively and concretely grasp the research hotspots and frontiers in the field of human resource management, and understand the evolution process of frontiers, in the CiteSpace co-occurrence knowledge map interface, select the burstness button under the control panel, and click view to get Figure 3. Figure 4 shows the top 15 keyword co-occurrence surge nodes and their related information from 2011 to 2021. In the figure, the aggravating part of the timeline is a visual representation of the starting and ending years of the keyword surge. As can be seen from Figure 4, the hot keywords in the field of human resource management will continue to evolve from 2011 to 2021. In 2011, we began to focus on the keywords of management and corporate culture; in 2011, we began to focus on the keywords of human resource management system and coal enterprises; in 2013, we began to focus on the keywords of logistics enterprises and salary management; in 2014, we began to focus on the keywords of human resource management practice and innovation performance; in 2015, we began to focus on the keywords of big data, and continue to focus on 2021 In 2016, human resource management intensity, tea enterprises, tea enterprises and sharing economy were the key words, among which, the intensity of human resource management was more concerned and continued to be concerned until 2021; in 2017 and 2018, human resource allocation and nursing management were the key words; in 2019, enterprise human resource management, science and technology human resource and artificial intelligence were the key words Human resource management research. 


\section{Top 20 Keywords with the Strongest Citation Bursts}

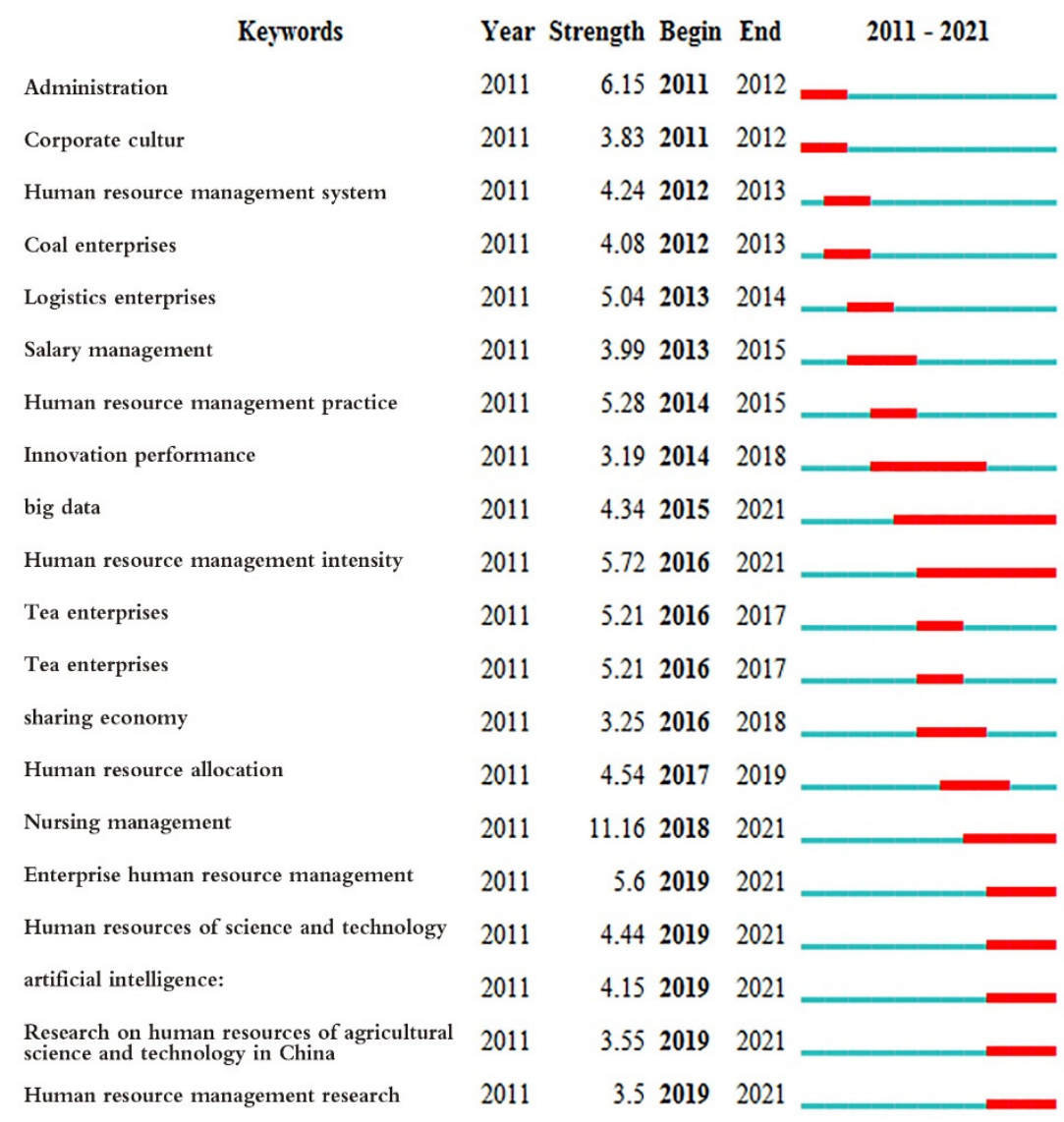

Figure3 Keyword mutation in human resource management research

\section{Conclusions}

In this study, 2724 articles published in the field of human resource management from 2011 to 2021 were retrieved from CNKI database as data samples, and CiteSpace was used to analyze these data and draw the corresponding intuitive and visualized knowledge map.

Through the visualization results of literature data analysis, we can intuitively get the distribution of the authors, institutions and their cooperation in this field. We can draw the conclusion that the publishing institutions are mainly the management schools and business schools of undergraduate universities, and most of them are in developed areas such as Beijing and Jiangsu Province. Through the keyword analysis, we can get the research hotspots and their evolution process. At the same time, we can get the conclusion by cluster analysis The knowledge map of human resource management intuitively and vividly shows 12 topic clusters in the research field of human resource management, which are the hot spots in the current research of human resource management. Next, we can further study these clustering directions and the frontier key development directions in the field of human resource management, so as to serve and guide the theory and practice of human resource management in China.

\section{References}

1. Li J, Chen C.M. (2017) CiteSpace: Research on scientific text mining and visualization. Capital University of economics and trade press, Beijing

2. NingB.R. (2020) risk challenge and resolution strategy in the new era of human resource management [J]. Leadership science, 24:91-94

3. Xie X.Y, Zuo Y.H, Hu Q.J. (2020) human resource management in the digital age: from the perspective of interaction between human and technology [J]. Management world, 37:200-216

4. Liu F, Wu H. W, Liu Z.(2006) A review of human resource management in China[J]. Scientific management research,24:86-89

5. Zhou Z.X.(2020) Research status and trend analysis on publishing ethics of Chinese Sci tech journals based on CiteSpace[J].Academic exploration, 8:129135

6. Li Z.X, Qi Y.X, Wang Y.D. (2017) visualization analysis of international human resource management research frontier based on scientific knowledge map [J]. Management science and engineering, 34:90-96 